\title{
WORKSHOP ON THE ANTARCTIC WIND FIELD
}

\author{
by John Turner and Azizan Abu Samah
}

T

he Antarctic is the windiest continent on Earth, with many of the coastal research stations affected by strong katabatic winds. The strength and persistence of the near-surface winds was noted by many of the early explorers (Fig. 1), and this feature has been perhaps the most intensively studied climatological element since then. In recent years there have been many advances in our understanding of the wind field both through the availability of data from automatic weather stations (AWSs) in remote locations and in improvements in numerical models.

For the last four years the Scientific Committee on Antarctic Research (SCAR) has been assessing our knowledge of the Antarctic wind field and trying to improve the representation of the winds in climate and numerical weather prediction (NWP) models. This meeting consisted of invited and submitted papers on many aspects of the Antarctic wind field. During the final morning there was a panel discussion that summarized our current understanding and considered the gaps in our knowledge.

OBSERVATIONS OF THE WIND FIELD. Ian Renfrew (University of East Anglia) considered the important question of what constitutes a katabatic wind, as opposed to other downslope winds. In the

AFFILIATIONS: TURNER-British Antarctic Survey, Cambridge, United Kingdom; ABU SAMAH-University of Malaya, Kuala Lumpur, Malaysia CORRESPONDING AUTHOR: John Turner, British Antarctic Survey, High Cross, Madingley Road, Cambridge CB3 0ET, United Kingdom E-mail:J.Turner@bas.ac.uk

DOI:10.|175/BAMS-88-5-72|

In final form 6 February 2007

C)2007 American Meteorological Society

\section{ANTARCTIC WIND FIELD WORKSHOP}

WHAT: Twenty research scientists and weather forecasters from seven countries met to review our understanding of Antarctic winds and to determine where future research is needed.

WHEN: 13-15 March 2006

WHERE: Kuala Lumpur, Malaysia

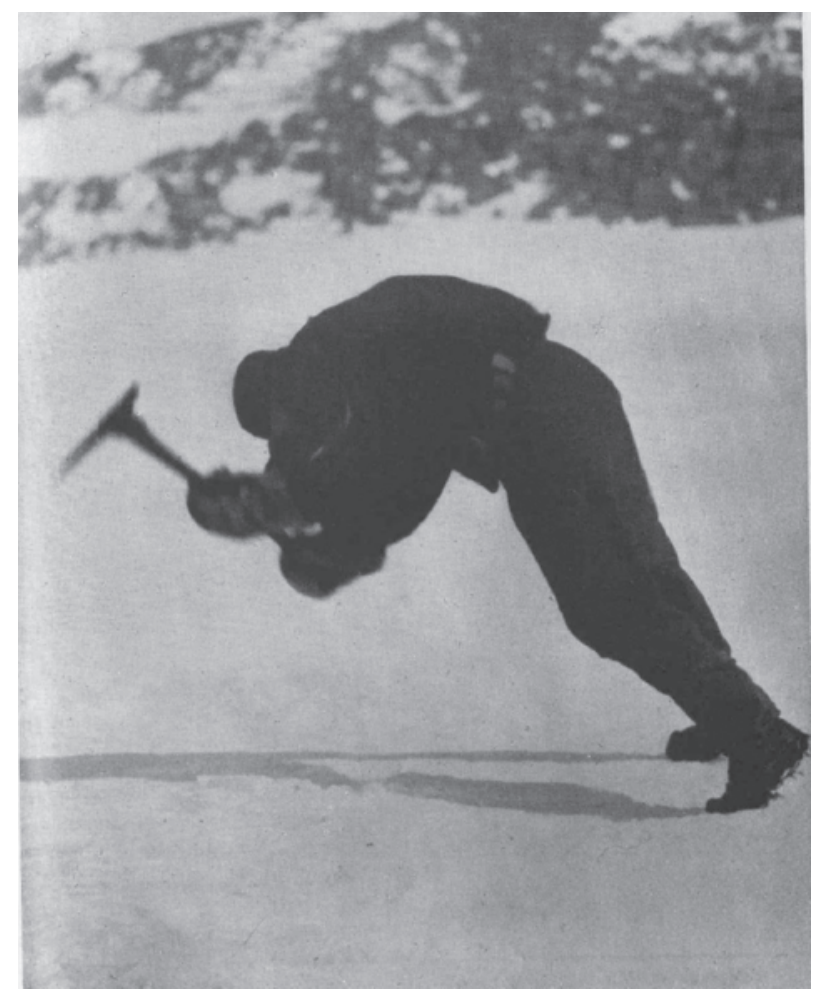

Fig. I. An early expeditioner struggles against the strong Antarctic wind. 
case of a katabatic wind, the emission of longwave radiation to space cools the surface and the boundary layer, leading to a horizontal pressure gradient along a line orthogonal to the coast. The pressure gradient forces the downslope flow. He concluded that surface winds over Antarctica are driven both by katabatic and synoptic-scale forcing mechanisms. $\mathrm{He}$ estimated that the surface flow is primarily katabatic $\sim 40 \%-50 \%$ of the time, but it "appears" katabatic $\sim 60 \%-70 \%$ of the time. Extensive work on katabatics has been done in Coats Land (Fig. 2), inland of Halley Station. An autonomous Doppler sodar deployed in Coats Land has provided a great deal of insight into the katabatic flow, which has proven to be relatively shallow. Upon reaching an ice shelf/sea ice, katabatic flows are often dammed by a pool of cold air.

Andrew Monaghan (Byrd Polar Research Center, Ohio State University) examined the impact of the extraordinary katabatic winds in Adélie Land on cyclonic activity. The strongest and most persistent winds in Antarctica have been measured in this region (Schwerdtfeger 1984). Earlier studies had shown that the ocean areas adjacent to coastal Adélie Land are regions of intense cyclogenesis, but they did not conclude whether katabatic winds played a role. This study used European Centre for Medium-Range Weather Forecasts (ECMWF) reanalysis fields during cases of autumn/winter cyclogenesis, and the results suggested that the winds do play a role, with a deep "tongue" of

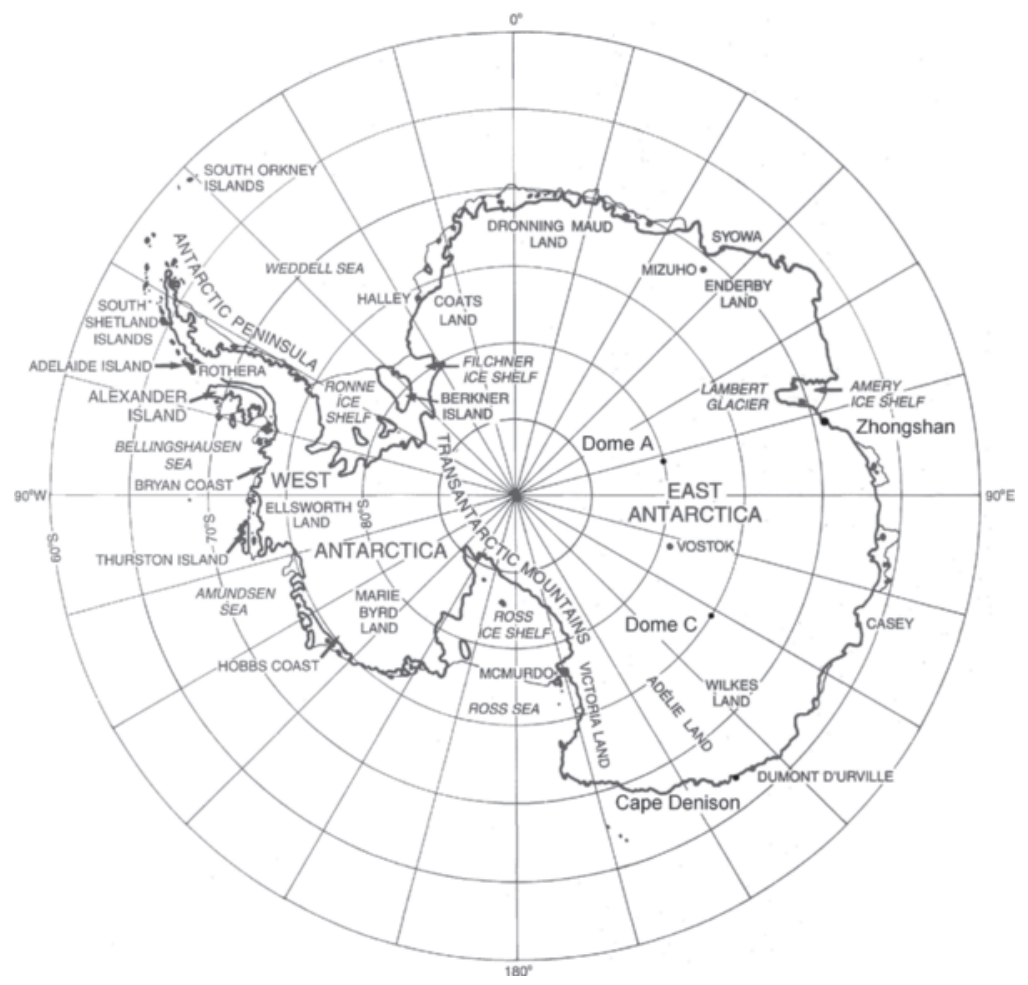

Fig. 2. Stations and locations in Antarctica referred to in the text. cold air extending from the continent during such events. A case study employing archived forecasts from the Antarctic Mesoscale Prediction System (AMPS) suggested that the winds interacted with the synopticscale low pressure system offshore to extend several hundred kilometers away from the coast.

Azizan Abu Samah (University of Malaya) outlined the observational studies that have been carried out by the Malaysian Antarctic Programme around Cape Denison and on the Ross Ice Shelf. They had been looking at severe and katabatic wind events over the period of 2002-04. They analyzed katabatic winds along the continental slope using AWS data from Dome C to Cape Denison from March 1990. Analysis of the AWS data showed coherent signatures of temperature, pressure, and wind speed. The speed of propagation of the pressure signatures was found to be faster than the mean katabatic wind.

Sheeba N C (University of Malaya) further examined the interactions between katabatic winds and synoptic-scale weather systems. Her presentation focused on two strong wind events that occurred between the period of 14-16 May 2004 and 15-17 June 2004. She concluded that surges in the katabatic flow over the Ross Sea were linked to the synoptic forcing.

Observations of sastrugi (ridges on the snow surface aligned along the prevailing wind direction) are a powerful tool for investigating the climatology of the wind field in remote locations. Xiao Cunde (Chinese Academy of Meteorological Sciences) discussed sastrugi observations along a traverse from Zhongshan Station to Dome A. Snow pits were drilled at various locations along this line, and data on sastrugi numbers and height were gathered by counting and visual observations.

\section{MODELING NEAR-SURFACE WINDS ACROSS THE CON- TINENT. There were several pre-} sentations that considered the ability of the present generation of NWP and climate models to represent the Antarctic wind field. John Turner (British Antarctic Survey) considered the Antarctic wind field in the Third Hadley Centre Coupled OceanAtmosphere General Circulation Model (HadCM3). The model reasonably represents the winds, but in the Antarctic coastal region errors in the broad-scale surface pressure field 
indicate that the coastal easterlies are too strong. The downslope flow over the continent itself is slightly too strong because the surface temperatures are too low over the plateau. It was noted that errors in the model's tropical sea surface temperatures were responsible for the high-latitude pressure errors, indicating the highly coupled nature of the tropical-Antarctic teleconnections. Results from the model runs used in the Intergovernmental Panel on Climate Change (IPCC) Fourth Assessment were also presented. These suggested that the predicted warming over the interior of the Antarctic of the order of $0.3^{\circ}-0.5^{\circ} \mathrm{C}$ decade $^{-1}$ would result in a slight decrease in the strength of the downslope flow, especially during the summer months.

Renfrew stated that the katabatic flow can be well represented by high-resolution, limited-area numerical models, but their performance is highly sensitive to the boundary layer scheme used.

\section{FORECASTING ANTARCTIC WINDS. Marc} De Keyser (Royal Meteorological Institute of Belgium) discussed forecasting winds in the Antarctic. The forecasting problem is quite different over the ocean areas than on the continent itself. Over the ocean the NWP models have greater skill than in the Northern Hemisphere because of the simpler orography of the Southern Hemisphere. However, over the continent, and especially in the coastal region, sites are affected by local wind systems that many of the global models cannot capture. Forecasters, therefore, tend to adopt a nowcasting approach based on satellite imagery to predict the winds over the period up to 24 hours ahead. High-horizontal-resolution, limited-area NWP models [such as the U.S. Antarctic Mesoscale Prediction System (AMPS)] are starting to have skill in predicting surface winds in areas of complex orography.

\section{THE INTERNATIONAL POLAR YEAR.}

The IPY was discussed in several presentations. Model intercomparisons will be important during the International Polar Year (IPY), along with data impact studies. The establishment of a base at Dome A by the Chinese will provide valuable data in the interior. Andrew Monaghan discussed the IPY in relation to the major The Observing System Research and Predictability Experiment (THORPEX) project, which aims to advance our understanding of atmospheric weather systems and weather prediction. Many of the proposed IPY activities have the potential to improve our understanding of the Antarctic wind field.

The next meeting on the Antarctic wind field will be held at the SCAR Opening Science Conference, which will take place in St. Petersburg, Russia, over 7-11 July 2008.

ACKNOWLEDGMENTS. We are grateful to the Scientific Committee on Antarctic Research for sponsoring the workshop and funding the travel and accommodation costs of several of the participants. We would also like to thank the members of the Local Organizing Committee for making all the local arrangements.

\section{REFERENCES}

Schwerdtfeger, W., 1984: Weather and Climate of the Antarctic. Elsevier, 182 pp.

\section{RECOMMENDATIONS FROM THE MEETING}

- A new, higher-resolution horizontal field of the Antarctic near-surface winds should be created because the current fields do not have the resolution to resolve many of the smaller orographic features. This will require a high-quality digital elevation model (DEM). A resolution of $10 \mathrm{~km}$ is suggested; it also is needed to drive blowing snow models.

- We need to understand whether the output of the new generation of limited-area NWP models is better than that from the global models.

- There needs to be more verification of wind forecasts issued by the research stations.

- More research is needed in the cyclogenesis area off of Adélie Land, where there are close interactions between the winds and cyclonic systems.

- We need to study how the coastal polynyas have changed since the 1970 s in relation to the changing wind field.

- We recommend an investigation of the quality of the air-sea fluxes and comparisons with independent ship data.

- Changes in the Southern Hemisphere Annular Mode (SAM) have increased the westerly winds around the Antarctic. There needs to be further studies of the impact on the oceans.

- For the next global reanalyses, we need to ensure that all of the Antarctic data are included. We also need to know which data were included in the existing analyses. We need to investigate the possibility of having an Antarctic regional reanalysis of higher horizontal resolution.

- A climatology of Antarctic extreme events should be compiled.

- There should be more in situ aircraft data collected on atmospheric conditions within synoptic/mesoscale systems. Surface-based autonomous instruments are also of great value in addressing particular problems.

- Existing AWSs should be maintained and new equipment should be installed in areas such as Cape Denison.

- Further traverses should be carried out to collect data on sastrugi, surface type, dunes, etc.

- More regional observing programs such as the Antarctic Regional Interactions Meteorology Experiment (RIME) are needed to increase our knowledge of the wind field. 